\title{
How Individual Scholars Can Reduce the Rigor-Relevance Gap in Management Research
}

\author{
Joachim Wolf, Chair of Organization Theory and Design, University of Kiel, Germany, E-Mail: wolf@bwl.uni-kiel.de \\ Timo Rosenberg, Department of Organization Theory and Design, University of Kiel, Germany, E-Mail: rosenberg@bwl.uni-kiel.de
}

\begin{abstract}
This paper discusses a number of avenues management scholars could follow to reduce the existing gap between scientific rigor and practical relevance without relativizing the importance of the first goal dimension. Such changes are necessary because many management studies do not fully exploit the possibilities to increase their practical relevance while maintaining scientific rigor. We argue that this rigor-relevance gap is not only the consequence of the currently prevailing institutional context in the scientific system, but that individual scholars can reduce the gap between rigorous and practically relevant research by modifying their research work. Thus, most of our suggestions refer to individual scholars' research activities and relate to specific steps in the (empirical) research process. Our discussion does not imply that all management studies should be practically oriented; basic research will remain a very important part of management research. However, we believe that not enough management research studies are significantly influenced by practical relevance.
\end{abstract}

JEL-classification: M1O

Keywords: management, practical relevance, rigor, empirical research

Manuscript received April 13, 2011, accepted by Peter Walgenbach (Management) October 17, 2012.

\section{$1 \quad$ Introduction}

Different parties (i.e., business managers, executives, students, ministerial representatives) have often accused management scholars of not sufficiently considering the practical relevance of their research, and of merely pursuing scientific rigor instead. The scientific community has discussed this issue of the separating or uniting of rigor and practical relevance on different occasions and in numerous papers.

Given the analytical depth of the existing literature (e.g., Shrivastava 1987; Anderson, Herriot, and Hodgkinson 2001; Varadarajan 2003; Nicolai 2004; Baldridge, Floyd, and Markóczy 2004; Van de Ven and Johnson 2006; Daft and Lewin 2008; Kieser and Leiner 2009; Jarzabkowski, Mohrman, and Scherer 2010), this paper will only briefly discuss whether or why there is a gap between these two superordinate research goal categories in management research and how they are manifested. We aim to briefly outline the main reasons that may have led to the rigor-relevance problem. This paper considers management as a reality-oriented, activity-based academic discipline aiming to support business practice and, specifically, managers in their decision-making. Furthermore, the paper assumes that management studies' practical relevance can be increased - a perspective that is tenable given the empirical research findings. For instance, according to the study by Starkey and Madan (2001), most managers think that management scholars' research results are not very helpful, although they believe they could generally benefit from research. Similarly, Oesterle's (2006) inquiry shows managers believe that management journals are "not very appealing". Furthermore, according to this study, the 
more scientifically oriented a journal seems to be, the less useful it is perceived to be. Thus, the current paper will suggest ways to increase the practical relevance of management research. Furthermore, most management scholars assume that "applicability" is the most important criterion according to which the quality of their research should be evaluated (Marcus, Goodman, and Grazman 1995).

We are aware that some scholars are less optimistic regarding the possibility to integrate "rigor" and "practical relevance" in a single management research project. For example, based on Luhmann's (1995) system theory, Nicolai (2004), Kieser and Leiner (2009), as well as Rasche and Behnam (2009) argued that management practitioners and management scholars belong to two different systems that are each largely self-referential. According to this view, both systems tend to concentrate on their individual communication processes and filter information from the other system. External references can, therefore, only be integrated if these are based on the respective system's historical logic (Rasche and Behnam 2009). Furthermore, selfreferential communication processes are seen as a necessary condition of the systems' high levels of effectiveness. Although self-reference is undoubtedly a key element of Luhmann's system theory and social systems do indeed tend to filter and distort external information, we want to challenge these authors' system theory-based derivations with respect to the rigor-relevance debate in management research. We agree that there is currently little information exchange between the "management practice" and "research-oriented scientific community" systems and that Luhmann's reasoning might explain this. However, as yet there is no proof that the current self-referentiality in the managementoriented scientific system is a cause of, or even a necessary condition for, high levels of researchoriented effectiveness. For example, the field of inter-cultural management exemplifies that the communication processes between formerly selfreferential systems have led to a deeper understanding of the topics studied and to the development of more effective solutions (Dovidio, Eller, and Hewstone 2011). The same holds true for crossfunctional project teams used to effectively handle complex innovative problems in firms (Pinto, Pinto, and Prescott 1993; Keller 2001).

Moreover, Nicolai, Kieser, Leiner, Rasche, and
Behnam (see the sources cited below) argued that it is very difficult to bridge the rigor-relevance gap, as different goal criteria predominate in the two systems. Whereas scholars think in true-false categories, practitioners evaluate solutions in terms of whether they produce income (Luhmann 1982; Kieser and Leiner 2009), thus thinking in dimensions like usefulness or utility. We argue that this reasoning is somewhat too dogmatic, since in developing strategies and measures, managers also make logical, deliberate conclusions. Scientific reasoning, too, is not totally free of arguments referring to the usefulness or utility of specific plans of action. In management-oriented research processes, such thoughts are especially apparent if scholars study the effectiveness of measures with respect to firmrelevant goals. Given these arguments, the goals "rigor" and "practical relevance" are not as incommensurate as it is sometimes assumed in the area of management research (Avenier 2010). Indeed, "system theorists" admit that decoupling does not imply that communication between the two systems is impossible (Rasche and Behnam 2009). Thus, a wider consideration of the interests arising in the broader social and economic contexts in rigorous management research - which Pettigrew (2001) outlined as "mode 1.5" of research - seems possible. There is at least anecdotal evidence of research projects that scholars and practitioners conducted jointly and had published in highly ranked academic journals (Hodgkinson and Rousseau 2009).

Van de Ven and Johnson (2006) identified three different ways in which management research's rigor-relevance problem is framed: First, it can be framed as a knowledge transfer problem. The problem is one of translating and diffusing research knowledge into practice. The knowledge that management scholars produce "is not in a form that can be readily applied in contexts of practice" (p. 804). Second, it is argued that the rigor-relevance problem emerged because distinct kinds of knowledge are required for theory and practice. This framing is consistent with system theorists' view. According to the third framing, a gap emerged between rigor and relevance due to a knowledge production problem. Management scholars produce knowledge that does not sufficiently emphasize management's central concern, which is a general problem of design. Whilst the second type of framing identified by Van de Ven and Johnson leads to a more skeptical view 
in terms of whether rigor and relevance can be integrated, the first and third provide scope to integrate them.

Given our above view of the second way of framing, this paper aims at offering a range of applicable suggestions which might help management scholars (re)arrange their research in order to make it more useful for decision-makers within firms. Most of these suggestions refer to researchers' undertaking of management research projects and not to the institutional context in business schools (e.g., a specific university's incentive systems) or in the scientific community in general (e.g., academic journals' reviewing processes). Although there is no doubt that the institutional context also considerably influences the type of research management scholars prefer (the institutional aspects relevant for the rigor-relevance gap are discussed in, for instance, Vermeulen 2005; Frey 2007; Adler and Harzing 2009; and Kieser 2010), this paper mainly focuses on changes that individual scholars can make. We believe that even within the current institutional context, individual scholars are asked and have the duty to reduce the rigor-relevance gap in management research.

In the area of management, these suggestions are very important since it has been argued that the problem of research's insufficient practical relevance is most serious in this part of business administration (Rynes, Bartunek, and Daft 2001), despite leading scholars having long and unequivocally called for management research to have more practical relevance. For instance, as far back as 1993 Hambrick said in his AOM presidential address: "It is time for us to break out of our closed loop. It is time for us to matter." (Hambrick 1994, p. 13).

Some of the suggestions presented below focus on knowledge production; others on knowledge transfer. By doing so, most of our suggestions refer to the empirical type of management research. This is due to management research having increasingly become an empirical discipline and its many empirical studies having been criticized for their lack of practical relevance. Although the empirical type of management research is prioritized in this paper, we do not argue that theoretical research is of less practical relevance. Further, by developing suggestions for a more practically relevant management research, we do not refer to superficial, recipe-type management research. Moreover, it is not our intention to argue that every management research project has to be of an applied nature. In management research, as in other scientific areas, a division of labor between basic research and practice-oriented research is beneficial. Nevertheless, scholars who do not focus exclusively on basic research should systematically look for ways to improve the practical relevance of their research. These ways are discussed below; we use a normative style to present our suggestions in order to reveal the ways and to stimulate further discussion.

By urging management scholars to increase the practical relevance of their research, we do not ignore practitioners, who are also asked to help reduce the existing gap. Jarzabkowski, Mohrman, and Scherer (2010) described this situation as a network of relationships between the institutional members, scholars, and practitioners. In such networks, the various stakeholders might require either tight or loose connections. Although practitioners' efforts are also very important, the present paper focuses on the specific ways through which individual researchers could increase the practical relevance of their work, since this is part of their professional obligation to deliver results with a practical impact. Before we develop such suggestions, we briefly explain the terms "practical relevance" and "rigor". The paper concludes with a brief summary of the main suggestions and a brief outlook.

\section{Characteristics of the Terms "Rigor" and "Relevance"}

Although the terms "practical relevance" and "rigor" are frequently used in management research, they are ambiguously defined. Nonetheless, certain approaches to specify them are possible.

- The characteristics of rigorous studies refer to the theoretical and empirical parts of research projects. With respect to theory, rigor demands that the assumptions should be precisely specified, that the inferences/predictions should be logically derived, and that the domain (boundaries) of the reasoning undertaken should be articulated. With regard to a study's empirical part, rigor relates to matters such as the sample selection, the operationalization of theoretical constructs, the objectivity of the measurement, the interpretation of the results, and the potential for replication. In order to ensure rigor, studies have to be carefully conceptualized; their research process should be well structured; they should 
take the existing literature into account; and they should be solidly derived from more general theories. Such studies are usually based on existing research results. They are characterized by a high degree of methodical stringency and are predominantly quantitatively oriented. Typically, the level of data compression is high. Empirical evidence has to be found in order to test the hypotheses, which requires the investigation to be narrowly focused (Shrivastava 1987; Zmud 1996; Anderson, Herriot, and Hodgkinson 2001; Keleman and Bansal 2002). Rigorous research projects accentuate the research process and its accurate execution. It is therefore important to keep in mind that the innovativeness and substantive significance of the research results are not definitory characteristics of rigor.

- The practical relevance of management can be interpreted as management research's impact on managerial decision making (e.g., Nicolai and Seidl 2010). In their 2010 study, Nicolai and Seidl screened 450 articles in three leading academic management journals, empirically deriving three forms of practical relevance, which they classified as instrumental relevance, conceptual relevance, and legitimative relevance. Practically relevant studies can help firms increase their functionality, efficiency, and effectiveness. Following the frequently cited publication by Thomas and Tymon (1982), studies need to satisfy five attributes to be considered relevant for practitioners:

First of all, they have to focus on topics and phenomena with which practitioners in the firms are actually confronted (descriptive relevance). Second, they have to suggest success dimensions which are of importance to the respective businesses and which practitioners wish to influence (goal relevance). They should also investigate effects that result from the interaction between individuals, businesses, and the market in which they meet (Gulati 2007). Third, they should focus on variables that practitioners can influence or design (operational validity). Fourth, they should deliver results which practitioners cannot derive intuitively (nonobviousness). Practitioners should therefore find them novel or surprising to a certain degree. Fifth, these results should be available as soon as decision-makers face the problems to be solved (timeliness). According to this understanding, practical relevant research is more pertinent, pragmatic, feasible, and is focused on the results of the research process and its applicability (Benbasat and Zmud 1999). Since problem-solving is typically highly contextspecific, practically relevant studies are usually more adjusted to the peculiarities of individual cases. It could be argued that such an understanding of practical relevance leads to a narrow instrumental type of management research. Furthermore, because this view requires a broader understanding of practical relevance, management research is practically relevant as soon as it helps shift managers' understanding of their firms, their environment, and their jobs (Belfiore and Bennett 2008).

It is thus clear that it is no easy matter to integrate rigor and practical relevance in one management study. For instance, contrary to the target category of "timeliness," a methodically accurate approach takes time. Furthermore, a focus on manageable, result-oriented variables is often difficult, since firms may not (be able to) deliver the required data. Yet, despite these obvious limitations that prevent high achievement of both goal categories, it does seem possible to increase management research's practical relevance to a specific degree without jeopardizing the high levels of rigor that scholarly research requires. The analysis by Marcus, Goodman, and Grazman (1995) showed that there is no absolute trade-off between rigor and practical relevance; in their study, practitioners and scholars were asked to evaluate research publications according to their degree of rigor and practical relevance. The authors found a positive correlation between the two assessments. Among the highly rigorous studies, there were many which practitioners and scholars both considered as of high practical relevance (a corresponding result is reported by Ford, Duncan, Bedeian, Ginter, Rousculp, and Adams 2005).

Such findings are a motivation to present suggestions to improve practical relevance without losing academic rigor. It is important to keep in mind that we want to point out that these suggestions claim to increase the practical relevance, but not the scientific relevance of research. The latter describes the importance of studies for the knowledge generation processes of other scholars, and the interest they have in these studies (Daft and Lewin 2008). Although the question of scientific relevance is also important, scholars argue that the limited practical relevance of management studies is currently the 
bigger problem (see for instance the articles published in Special Issue 9/10 (2010) of Organization Studies).

\section{Suggestions regarding the Specific Stages of (Empirical) Management Research}

In the following sections, we will describe various opportunities to increase the practical relevance of management research. Since (empirical) research usually includes a consonant series of steps with which a researcher is confronted, regardless of the subject on which the research project focuses (e.g., Miller 1991; Mitchell and Jolley 2001; Creswell 2009), we organize our suggestions along the resulting stage model (e.g., Cooper 1982; Manly 1992). The suggestions refer to the following five stages of this research process:

- The development of a research idea, a research question, and a basic conceptualization of the research project,

- the specification of the research model and the elaboration of hypotheses,

- the data collection, analysis, and interpretation,

- the preparation of the research report, and

- the publication and diffusion of the research results.

\subsection{Development of a Research Idea, a Research Question, and a Basic Conceptualization of the Research Project}

(1) The first suggestion relates to the "descriptive relevance" criterion presented by Thomas and Tymon (1982): We believe that many of the current research-oriented publications do not sufficiently address those issues which are most urgent and important for current business practitioners. For example, it is surprising that research-oriented publications have very rarely covered the scandals that have surfaced in the business world during the last few years. The same holds true for subjects such as the "virtualization of the business world," "corporate restructuring," "terrorism and business," and many others, which research-oriented journals seldom discuss. Studies like those by Gopinath and Hoffman (1995), or Czinkota and Ronkainen (2009) show that such topics play a much bigger role in business practice than in research-oriented journals. Based on their analysis of citations of Academy of Management Review (AMR) articles, Corley and Gioia (2011) called for more practical utility, which they defined as "arising when theory can be directly applied to the problems practicing managers and other organizational practitioners face" (p. 18). Furthermore, a review of a large number of researchoriented journals has given us the impression that this discrepancy between academic and practitioner-oriented topics is more pronounced in more prestigious research-oriented journals. Although this phenomenon can be partly explained by top-tier journals' tendency to publish papers reporting on very sophisticated and time-intensive research projects, we think this discrepancy has contributed considerably to practitioners only relatively rarely reading scientific journals (Oesterle 2006).

Thus, in the future, business practitioners will need to be more involved in the first conceptual phases of research projects (Mohrman, Gibson, and Mohrman 2001). This change will stimulate a knowledge-generation process in which sensitivity to the research's impact is built in from the beginning and in which supply and demand factors can operate fruitfully (Gibbons, Limoges, Nowotny, Schwartzman, Scott, and Trow 1994). Nevertheless, practitioner involvement does not necessarily mean a research project jointly conducted by scholars and practitioners, since reports show that such collaborations are very difficult (Amabile, Patterson, Mueller, Wojcik, Kramer, Odomirok, and Marsh 2001). Instead, scholars should collect information on practitioners' views of important research topics in the conceptual phase. This suggestion, which is in line with Van de Ven and Johnson's (2006) call for an "engaged scholarship," seems necessary as empirical studies (Rynes, Bartunek, and Daft 2001) have showed that in fewer than $20 \%$ of the articles published in a top-tier journal, practitioners were involved in the conceptual phase of the relevant research projects.

Nevertheless, the involvement of practitioners in the process of defining research topics has been very controversial. Critics (e.g., Grey 2001; Kilduff and Kelemen 2001) raise two types of arguments: First, this activation of practitioners is seen as pointless, because management scholars already have many sources, for example, business newspapers and magazines, from which to gather the phenomena or issues of managerial concern. This argument is only partially useful, since most business newspapers and magazines only convey the most important 
questions relevant for business practice and it is not clear whether many management scholars use these information sources to determine their research topics. The second group of arguments contains the warning that the involvement of practitioners may have negative effects on the scholarly system. It is believed that business practitioners cannot provide useful hints since "business practice only sees what it sees." Consequently, management scholars who define research topics on the basis of information from practitioners are believed to be slanted towards problems already well known among business practitioners. They are thus unable to fulfill management research's utopistic function. Further, such behavior could run the risk of leading academic researchers to pursue managerial fads and fashions (Abrahamson 1991). Moreover, many practitioners may be unable to formulate research questions precisely and realistically enough, as they are unfamiliar with the scientific knowledge stock and the prevailing theoretic concepts. Finally, practitioners may tend to define very operational research goals. All of this would hinder more long-termoriented scientific progress. If scholars were to adopt this way to find research topics, their behavior and work would be similar to those of consultants.

These warnings should undoubtedly be taken seriously. Nevertheless, if scholars were to ignore practitioners' views as sources of ideas for research projects, this too would be problematic. This becomes obvious if one imagines practitioners' views not being considered at all in this first stage of research projects: Management scholars would define their research topics almost exclusively on the basis of information from the scientific community. Many scholars would only study those topics suggested in the final sections of articles in high-ranked publications (e.g., in their "avenues for future research"). Such behavior would not guarantee an acceptable level of practical relevance, since these suggestions are often developed by those with little real management experience and, thus, very limited knowledge of ongoing management practice. Most scholars publishing in high-ranked journals have no professional experience of those management positions where the topics of their research work occur and have to be dealt with. Further, such an approach might lead to only topics for which there is a theory in the scientific community being studied. If practitioners are not heard, it can be assumed that important business world topics will be ignored (Hambrick 2007).

In making this first suggestion, we do not want to argue that scholars should react mechanistically to practitioners' wishes and suggestions, or that the latter should deterministically drive their research projects. Furthermore, of course, scholars who want to deliver utopistic concepts should have the right to do so. Management scholars selecting research topics should nevertheless always consider if an idea is at least indirectly related to the business world. Thus, practitioners' inputs should be taken as suggestions for potential research topics. Finally, not all practitioners have helpful suggestions for academic research projects. Thus, a key challenge for management scholars wanting to collaborate with practitioners in order to identify research topics is to find leaders or managers who are truly looked up to. This is not a trivial task since conceptual thinking in business firms resides mainly at the higher hierarchical levels, but many top managers do not have sufficient time or the willingness to discuss research projects with management scholars.

Given the dynamics in the field and the heterogeneity of opinions, it would be helpful if practitioner suggestions for research topics could be collected regularly and systematically. Delphi surveys, which have to date been infrequently applied for this goal (Lyles 1990; Zahra and Pearce 1992; Czinkota and Ronkainen 2009), could be used to collect such information. In such surveys, managers should not be asked for their views on particular research projects, but a more open-ended, useful approach should be used. For example, they should be asked about the current issues that concern them and about major sources of uncertainty. Large professional organizations like the Academy of Management, the Academy of International Business, or the Strategic Management Society could undertake such structured surveys. In their journals (Academy of Management Journal (AMJ), Journal of International Business Studies (JIBS), Strategic Management Journal (SMJ)), these institutions could then report on the survey results. In addition to such an institution-based collection of information about practitioners' views, direct contacts between individual scholars and business managers, which currently appear to be less intense than formerly, should also serve as a means to identify future research topics with high practical relevance. 
(2) In a second postulate referring to the general conceptualization of management studies, we argue that we need more studies that retest existing research findings (Singh, Ang, and Leong 2003). Unlike other disciplines such as psychology, management lacks a cumulative research tradition (Benbasat and Zmud 1999). It is currently hardly possible for a management scholar to have a paper that does not contain a major conceptual innovation but retests existing empirical findings accepted in a high-ranked journal. Consequently, scholars are guided by the requirement to identify and fill an asyet-unknown research gap within the literature during their research project designs. This has led to management research having conceptualized and tested an almost infinite number of relationships between variables. Most of these new relationships are proven in terms of only one dataset. For example, Sørensen's (2002) finding that, in stable environments, strong culture firms perform more reliably than firms with a weaker corporate culture. This research result is frequently cited, although there is little empirical support in subsequent studies. Another example of an insight that has not been very well proven is Bartlett and Ghoshal's (1989) concept of the transnational solution. Based on own casestudy research, they argued that the transnational solution is economically superior to other strategic MNC orientations. In the field of international management, this finding is a widely accepted key element of subsequent research work, although no studies have tested this notion rigorously. Since the list of such examples could easily be extended by many other examples, it is often unclear to what extent the relationships postulated and confirmed in individual studies would hold in subsequent ones. In the management area, there is generally a host of research results based on only one study. Consequently, this discipline lacks a solid, confirmed stock of robust knowledge which can be introduced to practitioners as findings that they can trust and on which they can base their managerial decisions.

One way to solve this problem would be for the leading journals to show a greater willingness to publish methodically solid replication studies with strong underlying data bases that are better than the original studies in these respects. If these journals' editorial teams do not show such willingness - which is not unlikely - making the respective changes would also, as mentioned above, become a task of the major professional associations. For instance, these associations could release new (online) journals specializing in the publication of carefully crafted follow-up studies. These activities could be supported by an agreement between business school faculties: For young postdoctoral scholars interested in tenure positions, the business schools could develop the requirement that they not only publish a sufficient number of innovative, high-quality publications, but that they also demonstrate their capability to conduct a solid replication study, which could be published in such a newly established "retesting journal." We believe that this would at least give management research a realistic chance of becoming a "set discipline" with a more consolidated knowledge stock. Such an "upgrading" of retesting studies would also improve the possibilities of conducting meta-analyses in many areas of management research, as identical relationships would then be tested in several studies and not just one. This would again improve the reliability of management research findings. However, if such meta-analyses address not only scholars but also practitioners, their presentation style has to be adjusted (see suggestions 10 and 12).

\subsection{Specification of the Research Model and Elaboration of Hypotheses}

This phase of the research process covers the selection of the variables to be considered in the respective research project, as well as the conceptualization of relationships between them. At this stage, several changes are necessary to increase the practical relevance of the studies.

(3) We argue that it would be advantageous to more frequently study variables that practitioners can influence. A cursory inspection of papers published in research-oriented journals led us to assume that, in recent years, many management publications have focused on variables that business practitioners cannot influence. This might be due to the values currently being maximized in many research-oriented business schools being those of the academic base disciplines, for example, sociology, rather than vocational ones (Donaldson 1985, 1995). In order to test this assumption, we analyzed all 1388 hypotheses conceptualized and tested in the journals Administrative Science Quarterly (ASQ), Academy of Management Journal (AMJ), and Strategic Management Journal (SMJ) in 2007 and 2008. This analysis showed that, in the observation period, only $15.54 \%$ of the hypotheses published in 
the ASQ contained variables that practitioners can influence. In the case of the AMJ, the respective value is $22.19 \%$, while in the SMJ it is $26.36 \%$. A major reason for management research's regression to the world of non-manageable variables lies in academic journals having increased the requirements for contributions in terms of methodical rigor during the last few years. Consequently, the datasets have to be relatively large in order to allow the application of advanced statistical procedures and the solid testing of hypotheses. Further, to avoid doubt being cast on the data reliability, scholars are inclined to use publicly available databases (e.g., Data stream or Compustat) containing "official data". Yet, in the majority of the cases, these records do not reflect internal aspects, and specifically not the parameters that managers can control, but instead "the outer surface characteristics" of firms. The marketing field, which lies outside the management area, is a commendable exception since it has largescale, customer-oriented databases. Nevertheless, given the orientation of many leading-edge studies conducted in the management area, a reorientation of research is necessary if a higher level of practical relevance is to be achieved.

Within the research models, more scholars should therefore analyze variables that practitioners can influence, without ignoring other factors completely (Beyer and Trice 1982). Since data with such controllable parameters are rare as part of publicly available databases or purchasable sources, more management scholars should collect primary data directly from firms. We are fully aware that this will need some allowance with regard to the data reliability. It is also clear that this is a cumbersome approach and that much greater collaboration will be needed between scholars. However, if we want to increase management research's practical relevance, there is no realistic alternative. Furthermore, we believe that if certain studies are not realized, this can be justified as the remaining will be even more meaningful and useful.

(4) Next, we suggest that future management scholars should include performance variables more carefully in their research projects. Performance variables should be considered that are (a) conceptually clearly related to the topic studied, and (b) important for practitioners. The practical relevance of our research can only be increased by including outcome-oriented analyses despite all their associated conceptual and methodical prob- lems (Cheng and McKinley 1983). Performancerelated answers are among the first practitioners require. There is also a need to significantly modify performance analyses that currently predominate in many publications.

- (a) With respect to the first point, one might correctly point out that journals like the SMJ or AMJ frequently publish studies which regress measures of firm performance on the topic studied in the specific research project. However, we believe that too many of these studies continue to make the mistakes typical of many "success factor studies" conducted in the 1970 and 1980s. In these studies, a countless number of management variables and firm characteristics are statistically related to firms' general performance data without any careful a-priori conceptualization of the potential causality structures (Nicolai and Kieser 2002). Firms' general performance data was and is often considered as this is relatively easy to acquire. The "intellectual bridges" between the design variables and the performance variables are usually weak in these studies. Such research behavior does not only lead to few consistent results, but can also gravely damage the reputation of the whole field of empirical management research. Research on the relationship between firms' degree of internationalization and their performance (for a critique of this research, see Hennart 2007) is a good example of a research field in which many inconsistent, often weakly hypothesized, relationships are tested and published.

In order to overcome superficial analyses, future management scholars should avoid the "wild correlating" of larger numbers of theoretically unclear potential success factors. Careful conceptualizations of the relationships between potential performance drivers and performance variables are required. This implies that, during the conceptualization phase of their research projects, scholars have to meticulously explain which of the considered performance variables are, for whatever reason, likely to occur as a consequence of the observed design variables. In particular, such projects should focus on performance variables that are conceptually and consistently related to the design variables studied. These studies have to consider the theoretical body of knowledge available in the respective field. 
- (b) The inclusion of performance variables that are important for practitioners should be based on the insight that managers usually have to make decisions in the context of different stakeholder groups with their differing interests. Given this situation, it is still true that too few of the research models (conceptual frameworks) contain goal variables reflecting the outcome of managerial actions with respect to the goals of the different stakeholders associated with business firms. In particular, this means that management studies should not only relate the design variables to economic outcome variables, but also with outcome variables that mirror the interests of other stakeholder groups affected by the issue studied.

This call for more management studies that include carefully conceptualized outcome variables will not banish the skepticism in the scholarly community regarding such analyses. First, March and Sutton (1997) stated that the performance variables considered in a study always mirror the theory and the general world-view that the specific scholar uses and prefers. Given this phenomenon, and given that capacity restrictions hardly allow researchers to consider a broader spectrum of economic and social outcome variables in a single research project, the logical conclusion is that different researchers should study the different outcome consequences of identical managerial design variables. Second, in research projects, it is always difficult to allocate causes precisely to their outcome consequences. Among others, this is because many managers are skillful at smoothing out their firms' presented performance levels (Lewin, Weigelt, and Emery 2004), and because there are lag effects between many managerial actions and the intended outcomes.

One pragmatic approach to increase the probability of the fulfillment of these requests or indications might be for journal editors to only accept those outcome-oriented studies for publication that also discuss the logic of each design-success relationship in more detail and more convincingly than is currently done in many scholarly journals. This would ensure that the respective authors consider the assumed relationship very carefully. It would also allow the readers to assess the means-end relationships developed in the research report prudently. Overall, it is quite likely that if realistic success factors (i.e., variables explaining convincingly that they might influence the performance variables) are used and if the relationships between design and outcome variables are carefully conceptualized, it will be possible to surmount one of the main dilemmas of management research.

(5) We consider it important for management scholars to also seek dialogue with practitioners in this phase of their research projects. The project phase specifying the research model sets the course that can later be extremely difficult to correct. Hughes, Bence, Grisoni, O’Regan, and Wornham (2011) pointed out the importance of the dialogue between academics and practitioners and described several ways to start a bilateral engagement. In particular, practitioners should be contacted to obtain feedback on the assumed context-means relationships and means-end relationships that are part of the preliminary research models. One approach to collect feedback could be for scholars to approach practitioners with an open question (e.g., "In recent years your firm has shifted an increasing proportion of its value creation processes abroad. What do you think were the main reasons for this decision and development?"). By doing so, the scholars could obtain information on the causes managers believe drove their actions in the respective case. Of course, the causes that the interview partners mention are only based on their perception, but it remains to be seen that the relationships suggested and found in the literature are also only one part of the story. Similarly, scholars should seek information about the factors that are, in the practitioners' views, the main drivers of success. Again, the practitioners' views should only be regarded as one of several views to prevent scholars from merely reinforcing the business community's logics. However, in the scientific community, the contrary one-sided behavior seems to currently dominate: We tend to ignore the context-design-success logics in the minds of the business practitioners. Such information should be reflected during the process of revising the original version of the research model, which is usually mainly developed on the basis of academic literature. In a next step, the proposed research model could be presented to the practitioners. They could be asked to name those relationships they consider as lacking credibility and which should therefore be critically rethought.

The appropriateness of the research models could be evaluated according to the ways that (exploratory) information gathering were undertaken. The relevant practitioners will deliver a heterogeneous 
spectrum of assumptions, opinions, and ideas about the influencing factors in the research model and their consequences. In order to use this variety of views appropriately, preliminary exploratory studies should logically be carried out by means of Delphi surveys in order to obtain a more coherent pattern of practitioner answers. Furthermore, it is quite likely that, in an explicit and exhaustive form, practitioners will experience difficulties with naming the causal structures between the influencing and influenced factors. However, such a simple feedback loop can lead to significant insights even if only three or five practitioners are involved.

Gulati (2007) suggested discussing these preliminary research models with students in seminars and tutorials. This would help evaluate the practical suitability of the research models and their theoretical constructs. Burke and Rau (2010) followed this idea and underline that "teaching can enlighten our research (p. 132)." At first glance, this suggestion seems to be of limited value since most students lack sufficient professional experience and, in particular, have little experience in the field of managerial decision making to which a large part of management research is related. On the other hand, one could argue that the impartiality of students is an asset in this approach because it encourages a radical questioning of the variables and the relationships included in the preliminary models. Besides, in other academic fields (e.g., architecture and design), non-experts are traditionally asked to assess the ideas that experts propose. Furthermore, this would help scholars improve their ability to explain research projects in a pedagogically useful way. Finally, the students would become familiar with the contents of their professors' research work (they often only know them from classes).

\subsection{Data Collection, Analysis, and Interpretation}

Above, we noted many scholars' use of publicly available datasets, which very often do not include variables that business practitioners are able to control, over the last few years. Surveys among scholars have found that in only $34 \%$ of empirical management research projects' data is collected directly in firms (Berry, Klompmaker, McLaughlin, and Hill 1991). If the field of management research wants to be more than a descriptively oriented "sociology of firms," its proportion of datasets describing firms' internal structures and processes has to increase. However, in addition to this call for more frequent data collection directly in firms, several other modifications related to the collection, analysis, and interpretation of data are required.

(6) With respect to the analysis of empirical data, we suggest scholars concentrate less strongly on the determination of average relationships between variables. This suggestion refers specifically to the analysis of the relationships between the contextual factors and firms' design variables. The dominant, one-sided use of linear regression models that the overwhelming majority of quantitative empirical studies prefer, should be specifically complemented by the careful identification and analysis of outliers (Daft and Lewin 1990; March, Sproull, and Tamuz 1991). Scholars solely using linear regression models tend to identify firms' average and thus "normal" behavior for each contextual constellation. By doing so, they highlight the behavior of the ordinary, rather obscure firm. There can be no doubt that this kind of research is currently very dominant, which leads scholars tending to oppose the core task of any practically useful management research regarding developing ideas in respect of exceptional types of managerial strategies and actions, thus helping firms to obtain competitive advantage. Therefore, in the future, more empirical studies should try (1) to identify the main relationships between variables and (2) to focus on firms operating in specific situations far from the mainstream, to achieve success. McKelvey unfolded (2006) a similar idea. He argued that management research should focus much more on the extreme conditions that firms experience. He referred to earthquake research, which is not at all interested in the myriad of tiny earthquakes, but only in those with extreme levels leading to disasters. A more frequent study of extreme cases (outliers) would, as mentioned above, support management research's practical relevance, since managers' main task is to identify and capitalize on their firms' competitive advantages vis-à-vis those of rival firms. Further, a focus on positive outliers would enhance practitioners' ability to conduct model learning.

(7) With respect to the research methods used, we want to call for the more frequent application of qualitative research methods in management research (Bettis 1991). Large-scale quantitative empirical research, which yields models and hypotheses to be tested, rarely detects totally new phenomena and relationships. A principal reason for this is that 
new phenomena and relationships usually start to occur in only a single case or in very few cases (which hinders the application of quantitative research methods). However, discovering new phenomena and relationships is an important management research task, as this has developed rapidly in many sub-areas. Qualitative research focuses on such a single case or a few cases and seems most useful in progressive fields of study (e.g., information and communication technology and biotechnology) where knowledge structures develop very dynamically. If the models management scholars suggest and test lag behind business practice developments, business practitioners will not appreciate and apply them. Since their exploratory potential is seen as qualitative research methods' relative strength (Eisenhardt and Graebner 2007), this type of research might help increase the timeliness of management research. Siggelkow (2007) argued that qualitative research can contribute in three ways: First, it can be used to motivate a research question; second, it can inspire new ideas; and, third, it can be employed as an illustration. This call for the more frequent use of qualitative research methods is consistent with Gibbons, Limoges, Nowotny, Schwartzman, Scott, and Trow's (1994) line of reasoning. In addition, qualitative research projects generate knowledge in an application context (Nowotny, Scott and Gibbons 2001). Furthermore, flexibility and response time are currently considered crucial societal factors (Gibbons, Limoges, Nowotny, Schwartzman, Scott, and Trow 1994).

The more frequent use of qualitative research methods is expected to also lead to more creative research results (see Polzer, Gulati, Khurana, and Tushman's 2009 suggestion that a "full-cycle approach" to research should be established, pp. 283 et seq.). Typically, creative (inspiring) patterns of behavior develop in only a few cases and not occur simultaneously in many firms. Moreover, a sound understanding of creative solutions requires an indepth-analysis of the context from which they emerge. Currently, too many management scholars only undertake "normal research." The one-sided emphasis on methodical rigor has specifically resulted in articles in peer-reviewed journals often reporting on relationships between variables that are so obvious that any clear-thinking person can predict them. We consulted a recent issue of the Academy of Management Journal (we refer to this journal here and in the following as many journal rankings consider it the best empirical management journal worldwide) to provide examples of this problem. It will come as no surprise to practitioners to learn that the following hypothesis was confirmed: "Expatriate ability to transfer knowledge to a subsidiary (i.e., the ability to solve difficulties in the transfer process) has an indirect, positive relationship, via the knowledge received by the subsidiary, with the subsidiary's performance." (Chang, Gong, and Peng 2012, p. 931). Similarly, practitioners will question the need to test the following hypothesis empirically: “A team's relational resources are positively associated with the team's knowledge integration capability" (Gardner, Gino, and Staats 2012, p. 1002). Owing to these statements' very high degree of plausibility, they will accept them even if they are unproven. In our discipline, we have reached a situation comparable to what Gordon, Kleiman, and Hanie (1978) many years ago noted in respect of the field of psychology: In their study, non-psychologists were asked to predict the relationships between variables documented in 62 articles published in highly ranked organizational psychology journals. The respondents' predictions were correct in three of four cases, which underlines the criticized occurrence of research with trivial conjectures and results. Instead of wasting journal space by reporting relationships that are not really worth considering, research-oriented business journals should, to a greater extent, cover creative ideas, novel design approaches, and retestings. There can be no doubt that this would lead to an increase in practitioners' interest in research-oriented management publications.

Further, qualitative research promises practically relevant findings since this method uses different sources of evidence to demonstrate the full richness of the real-life context. It thus allows a deeper understanding of managers' decision-making situations (Eisenhardt 1989; Yin 2003). Further arguments support our call for the intensified use of qualitative research methods: First, the exploratory nature of this research type helps extend and specify the research models documented in the literature. Second, case studies emphasize the rich, real-world context in which the phenomena occur (Eisenhardt and Graebner 2007). Specifically, these methods promise a more accurate understanding of the causal mechanisms existing in reality. Third, this type of research is a better fit with the methods practition- 
ers use to obtain the knowledge they require for their daily operations. Fourth, qualitative research could be the way to explore outstanding types of managerial action as called for in our previous suggestion. Fifth, it should be noted that qualitative research articles are relatively often found among the most influential publications in management research. Examples of these studies are those by Mintzberg (1973), Edström and Galbraith (1977), Burgelman (1983), and Maurer and Ebers (2006), all of which are based on the qualitative research approach. Moreover, publications that build theory from cases are often regarded as the "most interesting” research (Bartunek, Rynes, and Ireland 2006). Given these relative strengths of qualitative research, it is not surprising that many practitioners accepted it better than they do quantitative research (Van de Vall, Bolas, and Kang 1976).

A frequent argument against case-study research is that it could lead to highly situative, individual, and idiosyncratic findings. This objection is correct insofar as an individual case cannot prove a theory (Siggelkow 2007). Nevertheless, scholars have developed ways to reduce the problem of case-study research's idiosyncrasy. Central to these suggestions is that several cases should be employed to allow the development of a replication logic. That is, each case serves as a distinct experiment that stands on its own as a unit of analysis. Like a series of related laboratory experiments, multiple cases are discrete experiments that serve as replications, contrasts, and extensions of the emerging theory. The theorybuilding process occurs via recursive cycling between the case data, emerging theory, and later, the extant literature (Eisenhardt and Graebner 2007).

However, our plea for more qualitative research should not be understood as an appeal to move away from quantitative, large-scale empirical research, as we are aware of qualitative research methods' specific boundaries (see Eisenhardt 1989; Siggelkow 2007). For example, the limits of their representativeness and their increased requirements with respect to scholars' informationprocessing capacities should never be underestimated. Nevertheless, the potential opportunities to create valuable knowledge through qualitative research methods and their better fit with practitioners' ways of analyzing situations seem to be reason enough to call for an increase in their application. Given the importance of both quantitative and qualitative research methods, the undertaking of quali- tative studies before conducting quantitatively oriented studies is another behavioral mode we would like to encourage. In management research, topic A is far too often studied qualitatively by scholar 1 , while topic B is studied quantitatively by scholar 2 . It thus seems logical that the same topic should be studied qualitatively first and thereafter with quantitative research methods, although not necessarily the same scholar.

It could be argued that this call for more qualitative research is somewhat inconsistent with our second suggestion that the number of retesting studies should be increased. Nevertheless, we believe that within the system of management research there is sufficient scope to consider each of these calls if one, for example, keeps the masses of new variable relationships in mind that are introduced year after year at management conferences. We believe that it would be very helpful if the sheer number of new variable relationships could be reduced and if the scholars were to invest their nascent energy in conducting more qualitative and undertaking more retesting research. The former would increase the chance that the knowledge stock is related to reality, while the latter would make the knowledge stock more robust.

(8) Management research would also gain practical relevance if management scholars were to use moderator hypotheses more carefully as an instrument. At first glance, this suggestion sounds surprising, since there are frequently no simple relationships between two variables in business practice. Instead, in most cases, their relationship depends on the value of a third variable. Further, it could be argued that due to the previous, moderator hypotheses have to be conceptualized and tested, as the management discipline's stock of knowledge often show "inconclusive results", and these inconsistencies have to be solved. Nevertheless, a screening of empirical articles published in recent years suggests that the development and testing of moderator hypotheses has become a fashionable trend, i.e., factual requirements have not initiated them. They are frequently used although, in the relevant field of variables, no inconsistent findings are reported in existing publications. We illustrate the tendency towards moderator hypotheses by referring to Shin, Kim, Lee, and Bian's (2012) study. First, based on consistent findings from frequently cited publications, the authors hypothesized that cognitive team diversity is positively related to individual team- 
member creativity (p. 200). Then, these authors motivated the development and testing of a more complex hypothesis - according to which this relationship is moderated by transformational leadership - by mentioning that: "To understand under what conditions individual team members better use the potential benefits of cognitive team diversity for their creativity, one should also contemplate team-level factors. Among the team contextual factors, leadership plays the dominant role in workplaces ...” (p. 201). We believe that this is a toosuperficial explanation of the need for the development and testing of a moderator hypothesis. Management research has reached a state in which only a minority of empirical papers refrain from using moderator hypotheses. Further, a large portion of moderator hypotheses seems to be developed in a data-driven manner and are "supported" by contrived logics. Many of these hypotheses seem to be complemented by post-hoc logics. For example, Shepherd, Patzelt, and Wolfe (2011) hypothesized: "Organization members with a strong restoration orientation have fewer negative emotions in response to project failure than those with a weaker restoration orientation when the period after the failure is short but [with] ... more negative emotions about the project failure when the period after the failure is long." (p. 1235).

It is interesting to note that moderator hypotheses are frequently supported in the studies in which they are introduced, but they are rarely retested in subsequent studies. Since most moderated variable relationships are not well confirmed, they derogate the robustness of management research's body of knowledge. In other words: Nowadays, management scholars confront business practitioners with a great deal of complex findings, the pertinence of which is called into question. This contradicts practitioners' and societies' intention to invest millions of Euros in management research because they expect this to result in robust knowledge. If we ask here for a careful use of moderator hypotheses, we do not want to argue against them per se, but theory needs to guide most of them much better and they have to be retested far more frequently.

(9) Finally, in this phase of the research process, scholars should also enhance their cooperation with business practitioners. Of course, the average practitioner might not be able to support scholars' decisions regarding methodical or technical questions referring to the analysis of data. However, practitioners can support the process of creating valid, reliable, and user-friendly instruments with which to collect data. Specifically, they can help increase the response rates of mail surveys and other data gathering methods. In the data analysis and interpretation phases, scholars should have regular meetings with practitioners. During these meetings, scholars should present and discuss their preliminary findings with the practitioners, and ask for alternative explanations of the detected phenomena and relationships (Rynes, Bartunek, and Daft 2001). There are signs that management research has in recent years not moved towards but away from this target state: In many research projects, web-based questionnaires are emailed to an unknown internet community, the questionnaire data are received electronically, student research assistants are responsible for transferring the data to Excel sheets, data analysis is undertaken without the essential apriori conceptualization, the ad-hoc-generated hypotheses are tested in a staccato-like application of statistical tools, while this testing undertaken with all computational methods available on the market, and the detected "findings" are not reflected on in cooperation with practitioners. Editors from various business administration journals informed us that they too believe that this has become a frequently used mode of behavior in the scientific community. Close contact with practitioners at this stage of the research project could help suppress such malpractices.

\subsection{Preparation of the Research Report}

In this phase, significant changes are also required to ensure a higher level of practical relevance. Especially, the research report should be presented in user-friendly form.

(10) We believe a clear and comprehensive definition of the central terms used in journal articles would also help increase their practical relevance (Varadarajan 2003). While transparent terminology is not specific to the enhancement of practical relevance, it is also a central requirement to achieve scientific rigor. But we believe that clear definitions are especially crucial for achieving practical relevance, since the terminology scholars typically use is generated by the academic system itself and often does not play a (significant) role in practitioners' discussions. In a field such as management research, practitioners are likely to have problems with the key terms that scholars prefer, because the 
discipline usually deals with abstract phenomena such as the "epistemic community," "cutthroat cooperation," "symbolic isomorphism," "ambidexterity," and "ecological embeddedness" (Colquitt and Zapata-Phelan 2007). Owing to their abstractness, these terms are not intuitively apparent to practitioners. Practitioners will have problems to understand such abstract terms, since they are not familiar with many other academic concepts related to them. Practitioners usually do not have a "conceptual hemisphere" of scientific concepts; they tend to think in terms of a different, more concrete concept setting. Thus, when defining central terms, scholars interested in delivering practically relevant research, should avoid regressing on abstract terms that are mainly used in academia. It is important to ensure that other encrypted terms cannot explain the provided definitions. It would also help if the key terms we use refer to the terminology that practitioners typically use. The use of concrete examples can also be very fruitful. A further reason for a clear and comprehensive definition of the content of the terms used is that in management research, even more than in many other disciplines, many of the terms are inconsistently used.

(11) Furthermore, scholars should extend and modify their journal articles by adding text that explains the practical relevance of their studies, as well as the resulting implications. Such extensions are important because they "force" the scholar to think in this direction (which is not always the case). It could be argued that many journals already require the inclusion of text specifying the managerial implications of the study presented. Although this is undoubtedly true, our request is not standard in the literature because the text on "managerial/practical implications" is frequently only repetitions and slight, sometimes tautological, reformulations of the key findings presented in previous parts of the paper. An example is the managerial implications presented by Lichtenthaler in his (2009) AMJ article: "Exploratory, transformative, and exploitative learning have complementary positive effects on profiting from external knowledge. Thus, an increase in one learning process may not have a positive effect independent of the other processes. Firms need the ability to assimilate, maintain, and apply external knowledge, and an excessive focus on one learning process likely has negative consequences ... By contrast, a balanced development of the learning processes positively affects innovation and perfor- mance in stable and dynamic environments. For a firm's competitors, it is challenging to imitate three complementary learning processes, which are less obvious than an individual process ... Thus, the complementarity of the learning processes emphasizes the opportunities of gaining and sustaining a competitive advantage by developing absorptive capacity. To actively develop the learning processes, firms need sufficient market knowledge in addition to prior technological knowledge." (p. 840).

To make the management implication section helpful for practitioners, scholars have to provide hints on how to implement their key findings in management practice. Here, scholars have to discuss the levers which practitioners can use to transform scholarly insight into business practice. We believe that too many studies are not precise enough regarding the modus operandi necessary to apply the respective research result in business firms. If scholars, for instance, conduct an empirical study on the relationship between organizational learning and absorptive capacity (see the mentioned Lichtenthaler study above), they should not only repeat the confirmed hypotheses, but at least roughly indicate how exploratory, transformative, and exploitative learning processes can be established within the firm, how external knowledge can be assimilated, maintained, and applied, and when a sufficient volume of market and technological knowledge is reached. If such specifications are not provided, the results are largely sterile. On the other hand, as already mentioned above, if scholars describe how their insights should be implemented in business practice, this could lead to a strange situation with people without considerable practical experience (= most scholars) being asked to specify the practical relevance of research results. A potential way of solving this problem would be for scholars to write these parts of their research reports in collaboration with practitioners. Ideally, a first draft could already be formulated in the design phase of the research project to ensure that it is aimed at practice-relevant questions from the very beginning (Gopinath and Hoffman 1995).

(12) Modifying the style of the language used in publications could be a major lever to increase the practical relevance of management research (Benbasat and Zmud 1999; Shapiro, Kirkman, and Courtney 2007). Management scholars - just like those in other disciplines - often prefer an artificial and complex, even cumbersome language. But a 
user-friendly language does also improve the diffusion of the respective research work in academia: Articles that are - regardless of their contents difficult to understand have a relatively small readership even among scholars. To increase practitioners' use of scientific publications, articles should be written in a verbal-argumentative style rather than in formal mathematical language. The sentences should be clearly and simply structured and should include brief definitions of those key terms which are only well known in a specific sub-discipline of management research (Gopinath and Hoffman 1995; Rynes, Bartunek, and Daft 2001). Gulati (2007) formulated this need for a change more generally and asks scholars to develop the ability to act as "bilingual interpreters" (p. 780 et seq.). A further argument for linguistic adaptations is that many compelling publications by extremely influential management scholars (e.g., Porter, Prahalad, Hamel, or Mintzberg) are written in a relatively easily digestible language that helps bridge the communication gap between science and practice.

However, in the management literature, such linguistic simplifications are controversial: It has been argued that the scientific community's established and more conceptually oriented language is fruitful insofar as its abstract and sometimes even ambiguous terminology stimulates creative thinking. Further, an adjustment of this language to practitioners' rather pragmatic language leads to a loss of this ability (Astley and Zammuto 1992). This allegation should be taken seriously, but it should also be stressed that the basic suggestion does not favor "sloppy jargon," only a clear linguistic style.

Leading research personalities publish their research findings in different outlets using different language styles, which is a model that could be followed to increase the practical relevance of management. Whilst these scholars' publications in academic journals are written in a more technical language, they tend to use a more figurative language in practice-oriented reports (for an interesting comparison of scientific and practice-oriented publications originating from the same project, see Keleman and Bansal (2002)). Consensus could also be found for the idea of adding reader-friendly summaries to articles to increase their practical relevance without harming their academic aspiration level (Benbasat and Zmud 1999). In this regard, we suggest that two different summaries should be added to each publication: one for the target group of scholars and the other for practice-oriented readers. The latter could be formulated in collaboration with practitioners.

\subsection{Publication and Diffusion of the Research Results}

In this section, we discuss suggestions related to the phase following the completion of the research report. Two aspects seem to be particularly important for this phase of the publication and diffusion of research results.

(13) First, we believe scholars should be aware of the transmission of their research results to practitioners as an element of their professional obligations. Many members of our discipline have not yet exploited the possibilities in this area consistently enough. They do not systematically cultivate their relationships with practitioners and when "selling" their research results. For example, during the data collection of empirical research projects, many scholars try to motivate practitioners to participate by promising to ultimately send them an executive summary. However, not all scholars keep this promise. Such promises should always be kept. Furthermore, scholars should use a communication style in these summaries that correspond to practitioners' expectations. Executive summaries specifically designed for this target group should largely focus on the project's research questions and the findings. In addition, scholars could improve the marketing of their PhD students' research results to practitioners. At the end of each dissertation project, they should ask $\mathrm{PhD}$ students for a short (e.g., no longer than two pages) summary of their $\mathrm{PhD}$ thesis that focuses on their projects' innovative findings and valueadding elements. The professor is then obliged to introduce this summary to the world of practitioners. We doubt whether such behavior is a standard part of $\mathrm{PhD}$ projects in our discipline.

It is interesting to note that such behavior is often (mis)interpreted as "ignoble hard-selling" in our scientific community. Nevertheless, within the community there are good examples of how the endeavor to diffuse results can be improved. Professors like Jay Barney, David Teece, and Scott Shane formed an extensive distribution network of different means of information technology to supply practice with their recent research results. Such activities require a great deal of energy and consistent action, but from our point of view this should lead to greater value in the long run. 
(14) Finally, management scholars should be much more consequent in contacting practitioners for feedback on completed research projects. The strengthening of practitioners' role in researchfocused feedback processes will add further criteria to the evaluation of management studies. This will help incorporate "a diverse range of intellectual interests as well as other social, economic or political ones" (Gibbons, Limoges, Nowotny, Schwartzman, Scott, and Trow 1994, p. 8) into the evaluation process. To achieve this, there should be more than mere general "goodwill-small-talk circles" of scholars and practitioners. More working sessions, during which these parties can discuss and critically review the results of specific research projects, are required. Some of our colleagues disclaim this idea, arguing that practitioners would have problems understanding the complex models typical of the scientific world and would thus be unable to provide useful feedback. However, such statements seem rather self-protecting: Even if practitioners are unable to follow all features of scientific models, they can still ask useful questions, which scholars interested in constructive criticism can take as starting points for further idea generation.

\section{Summary and General Statement}

This paper discussed a series of suggestions that could increase the practical relevance of management research without reducing its rigor. Most of these suggestions focus on the conceptualization, execution, and presentation of management scholars' research projects and not on their institutional context. This paper emphasizes individual scholars' work since we believe they have the opportunity to conduct their research projects in such a way that the practical relevance of these projects could be increased.

The discussion of these suggestions has shown that significant changes are necessary in the area of idea generation, in the area of testing ideas, as well as in the area of their presentation. If the practical relevance of management research is to increase, modifications will have to be made in all stages of the (empirical) research process.

An integrative view of these suggestions shows the advantages of close cooperation between scholars and practitioners. This insight is fully consistent with the results of the publications by Gibbons and colleagues (Gibbons, Limoges, Nowotny, Schwartzman, Scott, and Trow 1994; Nowotny, Scott, and Gibbons 2001). According to them, the generation of new knowledge is increasingly due to joint efforts by scholars and practitioners. This will help management research become "a contextualized science" (Nowotny, Scott, and Gibbons 2001, p. 90) and to advance its stock of insights from "reliable knowledge to socially robust knowledge" (pp. 167 et seq.). ${ }^{1}$

Moreover, the current paper has shown that if the scientific community is to reduce the rigorrelevance gap, it will have to master the challenge of increasing the creativity of the research results and the consistency of management research's body of knowledge. The integration of these two goals is not a trivial task. Nevertheless, management's scientific community should be able to reduce this conflict, as not all research projects have to be both highly creative and highly commensurable with the existing stock of knowledge.

It could be argued that the gap between rigorous and practically relevant research in the area of management emerged due to the predominance of largescale, quantitative, positivistic research. Merely adjusting this type of research according to suggestions like those we presented above would thus not be sufficient. Instead, many of quantitative management studies would have to be replaced by studies guided by the hermeneutic paradigm (Gadamer 1975). Although the above plea for the strengthening of qualitative research has argued that such hermeneutical approaches should more frequently be integrated into management research projects, we believe that quantitative research methods will remain very important in the area of management to attain a core body of knowledge tested in a larger number of firms. Thus, there is a need for developing ideas on how to improve this research method.

Moreover, in spite of the suggestions made above, we are fully aware that generating instrumentally usable knowledge is not the only management research goal. Conceptual and symbolic knowledge are also very important goal categories of management research (Astley and Zammuto 1992). Thus, the authors in no way argue that management research should be exclusively oriented towards practical relevance. Nevertheless, we need more man-

${ }^{1}$ We thank one of the reviewers for this remark. 
agement research that is not only rigorous, but also practically relevant.

And finally, in spite of all efforts, it would be almost impossible to close the rigor-relevance gap in management research totally. Nevertheless, it remains our goal to reduce the rigor-relevance gap as far as possible.

\section{Acknowledgements}

A first draft of this paper was written when Joachim Wolf served as a visiting professor at the Institute for the World Economy (IfW), Kiel. He offers his thanks to the IfW for supporting this research work. We also thank Peter Walgenbach, Department Editor of Business Research, and the anonymous reviewers for their very useful and insightful feedback.

\section{References}

Abrahamson, Eric (1991): Managerial Fads and Fashions: The Diffusion and Rejection of Innovations, Academy of Management Review, 16 (3): 586-612.

Adler, Nancy J. and Anne-Wil Harzing (2009): When Knowledge Wins: Transcending the Sense and Nonsense of Academic Rankings, Academy of Management Learning \& Education, 8 (1): 7295 .

Amabile, Teresa M., Chelley Patterson, Jennifer Mueller, Tom Wojcik, Steven J. Kramer, Paul W. Odomirok, and Mel Marsh (2001): Academic-Practitioner Collaboration in Management Research: A Case of Cross-Profession Collaboration, Academy of Management Journal, 44 (2): 418-431.

Anderson, Neil, Peter Herriot, and Gerald P. Hodgkinson (2001): The Practitioner-Researcher Divide in Industrial, Work, and Organisational (IWO) Psychology: Where Are We Now, and Where Do We Do From Here?, Journal of Occupational and Organizational Psychology, 74 (4): 391-411.

Astley, W. Graham and Raymond F. Zammuto (1992): Organization Science, Managers, and Language Games, Organization Science, 3 (4): 443-460.

Avenier, Marie-José (2010): Shaping a Constructivist View of Organizational Design Science, Organization Studies, 31 (09/10): 1229-1255.

Baldridge, David C., Steven W. Floyd, and Lívia Markóczy (2004): Are Managers From Mars and Academicians From Venus? Toward an Understanding of the Relationship Between Academic Quality and Practical Relevance, Strategic Management Journal, 25 (11): 1063-1074.

Bartlett, Christopher A. and Sumantra Ghoshal (1989): Managing Across Borders: The Transnational Solution, Harvard Business School Press: Boston, MA.

Bartunek, Jean M., Sara L. Rynes, and R. Duane Ireland (2006): What Makes Management Research Interesting, and Why Does It Matter?, Academy of Management Journal, 49 (1): 9-15.

Belfiore, Eleonora and Oliver Bennett (2008): The Social Impact of the Arts: An Intellectual History, Palgrave Macmillan: New York, NY.
Benbasat, Izak and Robert W. Zmud (1999): Empirical Research in Information Systems: The Practice of Relevance, MIS Quarterly, 23 (1): 3-16.

Berry, William L., Jay E. Klompmaker, Curtis P. McLaughlin, and Terry Hill (1991): Linking Strategy Formulation in Marketing and Operations: Empirical Research, Journal of Operations Management, 10 (3): 294-302.

Bettis, Richard A. (1991): Strategic Management and the Straightjacket: An Editorial Essay, Organization Science, 2 (3): 315-319.

Beyer, Janice M. and Harrison M. Trice (1982): The Utilization Process: A Conceptual Framework and Synthesis of Empirical Findings, Administrative Science Quarterly, 27 (4): 591-622.

Burgelman, Robert A. (1983): A Process Model of Internal Corporate Venturing in the Diversified Major Firm, Administrative Science Quarterly, 28 (2): 223-244.

Burke, Lisa A. and Barbara Rau (2010): The Research-Teaching Gap in Management, Academy of Management Learning and Education, 9 (1): 132-143.

Chang, Yi-Ying, Yaping Gong, and Mike W. Peng (2012): Expatriate Knowledge Transfer, Absorptive Capacity, and Subsidiary Performance, Academy of Management Journal, 55 (4): 927948.

Cheng, Joseph L.C. and William McKinley (1983): Toward an Integration of Organization Research and Practice: A Contingency Study of Bureaucratic Control and Performance in Scientific Settings, Administrative Science Quarterly, 28 (1): 85-100.

Colquitt, Jason A. and Cindy P. Zapata-Phelan (2007): Trends in Theory Building and Theory Testing: A Five-Decade Study of the Academy of Management Journal, Academy of Management Journal, 50 (6): 1281-1303.

Cooper, Harris M. (1982): Scientific Guidelines for Conducting Integrative Research Reviews, Review of Educational Research, 52 (2): 291-302.

Corley, Kevin G. and Dennis A. Gioia (2011): Building Theory About Theory Building: What Constitutes a Theoretical Contribution?, Academy of Management Review, 36 (1): 12-32.

Creswell, John W. (2009): Research Design: Qualitative, Quantitative, and Mixed Methods Approaches, $3^{\text {rd }}$ ed., Sage: Los Angeles, CA et al.

Czinkota, Michael R. and Ilkka A. Ronkainen (2009): Trends and Indications in International Business: Topics for Future Research, Management International Review, 49 (2): 249-265.

Daft, Richard L. and Arie Y. Lewin (1990): Can Organization Studies Begin to Break out of the Normal Science Straithjacket? An Editorial Essay, Organization Science, 1(1): 1-9.

Daft, Richard L. and Arie Y. Lewin (2008): Rigor and Relevance in Organization Studies: Idea Migration and Academic Journal Evolution, Organization Science, 19 (1): 177-183.

Donaldson, Lex (1985): In Defence of Organization Theory: A Reply to the Critics, Cambridge University Press: Cambridge, UK.

Donaldson, Lex (1995): American Anti-Management Theories of Organization: A Critique of Paradigm Proliferation, Cambridge University Press: Cambridge, UK.

Dovidio, John F., Anja Eller, and Miles Hewstone (2011): Improving Intergroup Relations Through Direct, Extended and Other Forms of Indirect Contact, Group Processes \& Intergroup Relations, 14 (2): 147-16o. 
Edström, Anders and Jay R. Galbraith (1977): Transfer of Managers as a Coordination and Control Strategy in Multinational Organizations, Administrative Science Quarterly, 22 (2): 248-263.

Eisenhardt, Kathleen M. (1989): Building Theories from Case Study Research, Academy of Management Review, 14 (4): 532550 .

Eisenhardt, Kathleen M. and Melissa E. Graebner (2007): Theory Building from Cases: Opportunities and Challenges, Academy of Management Journal, 50 (1): 25-32.

Ford, Eric W., W. Jack Duncan, Arthur G. Bedeian, Peter M. Ginter, Matthew D. Rousculp, and Alice M. Adams (2005): Mitigating Risks, Visible Hands, Inevitable Disasters, and Soft Variables: Management Research That Matters to Managers, Academy of Management Executive, 19 (4): 24-38.

Frey, Bruno S. (2007): Evaluierungen, Evaluierungen ... Evaluitis, Perspektiven der Wirtschaftspolitik, 8 (3): 207-220.

Gadamer, Hans-Georg (1975): Truth and Method, Seabury Press: New York, NY.

Gardner, Heidi K., Francesca Gino, and Bradley R. Staats (2012): Dynamically Integrating Knowledge in Teams: Transforming Resources into Performance, Academy of Management Journal, 55 (4): 998-1022.

Gibbons, Michael, Camille Limoges, Helga Nowotny, Simon Schwartzman, Peter Scott, and Martin Trow (1994): The New Production of Knowledge: The Dynamics of Science and Research in Contemporary Societies, Sage: London et al.

Gopinath, C. and Richard C. Hoffman (1995): A Comment on the Relevance of Strategy Research, in: Paul Shrivastava and Charles Stubbart (eds.): Challenges From Within the Mainstream, Greenwich, 93-110.

Gordon, Michael E., Lawrence S. Kleiman, and Charles A. Hanie (1978): Industrial-Organizational Psychology: "Open the Ears, o House of Israel”, American Psychologist, 33 (10): 893-905

Grey, Christopher (2001): Re-imagining Relevance: A Response to Starkey and Madan, British Journal of Management, 12 (Special Issue): 27-32.

Gulati, Ranjay (2007): Tent Poles, Tribalism, and Boundary Spanning: The Rigor-Relevance Debate in Management Research, Academy of Management Journal, 50 (4): 775-782.

Hambrick, Donald C. (1994): 1993 Presidential Address: What if the Academy Actually Mattered?, Academy of Management Review, 19 (1): 11-16.

Hambrick, Donald C. (2007): The Field of Management's Devotion to Theory: Too Much of a Good Thing?, Academy of Management Journal, 50 (6): 1346-1352.

Hennart, Jean-Francois (2007): The Theoretical Rationale for a Multinationality-Performance Relationship, Management International Review, 47 (3): 423-452.

Hodgkinson, Gerard P. and Denise M. Rousseau (2009): Bridging the Rigour-Relevance Gap in Management Research: It's Already Happening!, Journal of Management Studies, 46 (3): 534-546.

Hughes, Tim, David Bence, Louise Grisoni, Nicholas O’Regan, and David Wornham (2011): Scholarship That Matters: Academic Practitioner Engagement in Business and Management, Academy of Management Learning \& Education, 10 (1): 40-57.

Jarzabkowski, Paula, Susan Albers Mohrman, and Andreas Georg
Scherer (2010): Organization Studies as Applied Science: The Generation and Use of Academic Knowledge About Organizations - Introduction to the Special Issue, Organization Studies, 31 (9/10): 1189-1207.

Kelemen, Mihaela and Pratima Bansal (2002): The Conventions of Management Research and Their Relevance to Management Practice, British Journal of Management, 13 (2): 97-108.

Keller, Robert T. (2001): Cross-Functional Project Groups in Research and New Product Development: Diversity, Communications, Job Stress, and Outcomes, Academy of Management Journal, 44 (3): 547-555.

Kieser, Alfred (2010): Unternehmen Wissenschaft?, Leviathan, 38 (3): $347-367$.

Kieser, Alfred and Lars Leiner (2009): Why the Rigour-Relevance Gap in Management Research is Unbridgeable, Journal of Management Studies, 46 (3): 516-533.

Kilduff, Martin and Mihaela Kelemen (2001): The Consolations of Organization Theory, British Journal of Management, 12 (Special Issue): 55-59.

Lewin, Arie Y., Carmen B. Weigelt, and James B. Emery (2004): Adaptation and Selection in Strategy and Change: Perspectives on Strategic Change in Organizations, in: Marshall S. Poole and Andrew H. Van de Ven (eds.): Handbook of Organizational Change and Innovation, Oxford University Press: Oxford, 108160.

Lichtenthaler, Ulrich (2009): Absorptive Capacity, Environmental Turbulence, and the Complementarity of Organizational Learning Processes, Academy of Management Journal, 52 (4): 822-846.

Luhmann, Niklas (1982): The Differentiation of Society, Columbia University Press: New York, NY.

Luhmann, Niklas (1995): Social Systems, Stanford University Press: Stanford, CA.

Lyles, Marjorie A. (1990): A Research Agenda for Strategic Management in the 1990s, Journal of Management Studies, 27 (4): 363-375.

Manly, Bryan F. J. (1992): The Design and Analysis of Research Studies, Cambridge University Press: Cambridge, UK.

March, James G., Lee S. Sproull, and Michal Tamuz (1991): Learning from Samples of One and Fewer, Organization Science, 2 (1): 1-13.

March, James G. and Robert I. Sutton (1997): Organization Performance as a Dependent Variable, Organization Science, 8 (6): 698-706.

Marcus, Alfred A., Robert S. Goodman, and David N. Grazman (1995): The Diffusion of Strategic Management Frameworks, in: Paul Shrivastava and Charles Stubbart (eds.): Challenges From Within the Mainstream, Greenwich, 115-145.

Maurer, Indre and Mark Ebers (2006): Dynamics of Social Capital and Their Performance Implications: Lessons From Biotechnology Start-Ups, Administrative Science Quarterly, 51 (2), 262292.

McKelvey, Bill (2006): Van de Ven and Johnson's "Engaged Scholarship": Nice Try, But ..., Academy of Management Review, 31 (4): 822-829.

Miller, Delbert C. (1991): Handbook of Research Design and Social Measurement, $5^{\text {th }}$ ed., Sage: Newbury Park, CA et al. 
Mintzberg, Henry (1973): The Nature of Managerial Work, Harper \& Row: New York, NY.

Mitchell, Mark and Janina Jolley (2001): Research Design Explained, $4^{\text {th }}$ ed., Harcourt College Publishers: Fort Worth, TX et al.

Mohrman, Susan Albers, Cristina B. Gibson, and Allan M. Mohrman Jr. (2001): Doing Research That Is Useful to Practice: A Model and Empirical Exploration, Academy of Management Journal, 44 (2): 357-375.

Nicolai, Alexander T. (2004): Der "trade-off" zwischen "rigour" und "relevance" und seine Konsequenzen für die ManagementWissenschaften, Zeitschrift für Betriebswirtschaft, 74 (2): 99-118.

Nicolai, Alexander T. and Alfred Kieser (2002): Trotz eklatanter Erfolglosigkeit: Die Erfolgsfaktorenforschung weiter auf Erfolgskurs, Die Betriebswirtschaft, 62 (6): 579-596.

Nicolai, Alexander T. and David Seidl (2010): That's Relevant! Different Forms of Practical Relevance in Management Science, Organization Studies, 31 (09/10): 1257-1285.

Nowotny, Helga, Peter Scott, and Michael Gibbons (2001): ReThinking Science: Knowledge and the Public in an Age of Uncertainty, Polity Press: Cambridge, UK et al.

Oesterle, Michael-Jörg (2006): Wahrnehmung betriebswirtschaftlicher Fachzeitschriften durch Praktiker, Die Betriebswirtschaft, 66 (3): 307-325.

Pettigrew, Andrew M. (2001): Management Research After Modernism, British Journal of Management, 12 (Special Issue): 61-70.

Pinto, Mary Beth, Jeffrey K. Pinto, and John E. Prescott (1993): Antecedents and Consequences of Project Team Cross-Functional Cooperation, Management Science, 39 (10): 1281-1297.

Polzer, Jeffrey T., Ranjay Gulati, Rakesh Khurana, and Michael L. Tushman (2009): Crossing Boundaries to Increase Relevance in Organizational Research, Journal of Management Inquiry, 18 (4): $280-286$.

Rasche, Andreas and Michael Behnam (2009): As If It Were Relevant: A Systems Theoretical Perspective on the Relation Between Science and Practice, Journal of Management Inquiry, 18 (3): 243-255.

Rynes, Sara L., Jean M. Bartunek, and Richard L. Daft (2001): Across the Great Divide: Knowledge Creation and Transfer Between Practitioners and Academics, Academy of Management Journal, 44 (2): 340-355.

Shapiro, Debra L., Bradley L. Kirkman, and Hugh G. Courtney (2007): Perceived Causes and Solutions of the Translation Problem in Management Research, Academy of Management Journal, 50 (2): 249-266.

Shepherd, Dean A., Holger Patzelt, and Marcus Wolfe (2011): Moving Forward From Project Failure: Negative Emotions, Affective Commitment, and Learning From the Experience, Academy of Management Journal, 54 (6): 1229-1259.

Shin, Shung J., Tae-Yeol Kim, Jeong-Yeon Lee, and Lin Bian (2012): Cognitive Team Diversity and Individual Team Member Creativity: A Cross-Level Interaction, Academy of Management Journal, 55 (1): 197-212.

Shrivastava, Paul (1987): Rigor and Practical Usefulness of Research in Strategic Management, Strategic Management Journal, 8 (1): 77-92.
Siggelkow, Nicolaj (2007): Persuasion With Case Studies, Academy of Management Journal, 50 (1): 20-24.

Singh, Kulwant, Siah Hwee Ang, and Siew Meng Leong (2003): Increasing Replication for Knowledge Accumulation in Strategy Research, Journal of Management, 29 (4): 533-549.

Sørensen, Jesper B. (2002): The Strength of Corporate Culture and the Reliability of Firm Performance, Administrative Science Quarterly, 47 (1): 70-91.

Starkey, Ken and Paula Madan (2001): Bridging the Relevance Gap: Aligning Stakeholders in the Future of Management Research, British Journal of Management, 12 (Special Issue): S3S26.

Thomas, Kenneth W. and Walter G. Tymon Jr. (1982): Necessary Properties of Relevant Research: Lessons From Recent Criticisms of the Organizational Sciences, Academy of Management Review, 7 (3): 345-352.

Van de Vall, Mark, Cheryl Bolas, and Tai S. Kang (1976): Applied Social Research in Industrial Organizations: An Evaluation of Functions, Theory, and Methods, Journal of Applied Behavioral Science, 12 (2): 158-177.

Van de Ven, Andrew H. and Paul E. Johnson (2006): Knowledge for Theory and Practice, Academy of Management Review, 31 (4): 802-821.

Varadarajan, P. Rajan (2003): Musings on Relevance and Rigor of Scholarly Research in Marketing, Journal of the Academy of Marketing Science, 31 (4): 368-376.

Vermeulen, Freek (2005): On Rigor and Relevance: Fostering Dialectic Progress in Management Research, Academy of Management Journal, 48 (6): 978-982.

Yin, Robert K. (2003): Case Study Research, $3^{\text {rd }}$ ed. Sage: Newbury Park, CA et al.

Zahra, Shaker A. and John A. Pearce (1992): Priorities of CEOs and Strategic Management Professors for Future Academic Research, Journal of Management Issues, 14 (2): 171-189.

Zmud, Robert W. (1996): Editor's Comments: On Rigor and Relevancy, Management Information Systems Quarterly, 20 (3): 37.

\section{Biographies}

Dr. Joachim Wolf is the Chair of Organization Theory and Design at the Institute of Business Administration of the University of Kiel. His research centers around organization structures of multinational companies, especially the use of matrix structures. A further focus of Dr. Wolf's work is the practical relevance of business research. His work has been published in journals including International Business Review, International Journal of Human Resource Management, and Strategic Management Journal. He is Co-Editor-in-Chief of Management International Review.

Timo Rosenberg is a doctoral student at the Department of Organization Theory and Design at the Institute of Business Administration of the University of Kiel. His doctoral dissertation project is on networks among the (foreign) subsidiaries of multinational companies. 